\title{
Nanotoxicity comparison of four amphiphilic polymeric micelles with similar hydrophilic or hydrophobic structure
}

Bo Zhao ${ }^{1}$, Xue-Qing Wang ${ }^{1 *}$, Xiao-You Wang ${ }^{1}$, Hua Zhang ${ }^{1}$, Wen-Bing Dai ${ }^{1}$, Jun Wang ${ }^{3}$, Zhen-Lin Zhong ${ }^{4}$, Hou-Nan $\mathrm{Wu}^{2^{*}}$ and Qiang Zhang ${ }^{\text {* }^{*}}$

\begin{abstract}
Background: Nanocarriers represent an attractive means of drug delivery, but their biosafety must be established before their use in clinical research.

Objectives: Four kinds of amphiphilic polymeric (PEG-PG-PCL, PEEP-PCL, PEG-PCL and PEG-DSPE) micelles with similar hydrophilic or hydrophobic structure were prepared and their in vitro and in vivo safety were evaluated and compared.

Methods: In vitro nanotoxicity evaluations included assessments of cell morphology, cell volume, inflammatory effects, cytotoxicity, apoptosis and membrane fluidity. An umbilical vein cell line (Eahy.926) and a kind of macrophages (J774.A1) were used as cell models considering that intravenous route is dominant for micelle delivery systems. In vivo analyses included complete blood count, lymphocyte subset analysis, detection of plasma inflammatory factors and histological observations of major organs after intravenous administration to KM mice.

Results: All the micelles enhanced inflammatory molecules in J774.A1 cells, likely resulting from the increased ROS levels. PEG-PG-PCL and PEEP-PCL micelles were found to increase the J774.A1 cell volume. This likely correlated with the size of PEG-PG-PCL micelles and the polyphosphoester structure in PEEP-PCL. PEG-DSPE micelles inhibited the growth of Eahy.926 cells via inducing apoptosis. This might relate to the structure of DSPE, which is a type of phospholipid and has good affinity with cell membrane. No evidence was found for cell membrane changes after treatment with these micelles for $24 \mathrm{~h}$. In the in vivo study, during 8 days of 4 time injection, each of the four nanocarriers altered the hematic phase differently without changes in inflammatory factors or pathological changes in target organs.
\end{abstract}

Conclusions: These results demonstrate that the micelles investigated exhibit diverse nanotoxicity correlated with their structures, their biosafety is different in different cell model, and there is no in vitro and in vivo correlation found. We believe that this study will certainly provide more scientific understandings on the nanotoxicity of amphiphilic polymeric micelles.

Keywords: Nanotoxicity, Amphiphilic polymeric micelles, J774.A1 cells, Eahy.926 cells, KM mice

\footnotetext{
* Correspondence: wangxq@bjmu.edu.cn; wuhounan@bjmu.edu.cn;

zqdodo@bjmu.edu.cn

${ }^{1}$ State Key Laboratory of Natural and Biomimetic Drugs, School of

Pharmaceutical Sciences, Peking University, Beijing 100191, China

${ }^{2}$ Medical and Healthy Analytical Center, Peking University, Beijing 100191,

China

Full list of author information is available at the end of the article
} 


\section{Background}

Nanomaterials exhibit a wide range of applications in different aspects of human life [1]. In medical and pharmaceutical fields, nanomaterials are packaged into different nanocarriers for biosensing, magnetic resonance imaging, optical detection, and drug delivery systems, among others [2-8]. The accelerating use of nanomaterials increases the likelihood of exposure in humans. Therefore, understanding the biosafety of nanomaterials is a necessity for building nanotechnology systems.

Many in vitro and in vivo studies have recently been conducted to demonstrate that nanomaterials in direct contact with cell surfaces may lead to several types of damages. Cell visualization appears to be the simplest and the most method of observing direct toxicity on cells. In a study of Yen et al., an increase in the size of the macrophages and a decreasing in cell population were observed after treatment with $\mathrm{Au}$ and $\mathrm{Ag}$ nanoparticles at $\geq 10 \mathrm{ppm}$ [9]. Some toxicological in vitro studies have reported that nanomaterials can influence reactive oxygen species (ROS) formation [10]. For example, Park et al. reported that the toxicity of $\mathrm{ZnO}-\mathrm{RT}$ and $\mathrm{ZnO}-60$ was related to ROS formation [11]. Direct cellular toxicity, which may be induced by certain nanomaterials, is another important sign of toxicity. In the study of Tian et al., single-and multi-walled carbon nanotubes (SWCNTs and MWCNTs) were found to be toxic to human cells $[12,13]$. Certain studies have investigated further influences of nanomaterials on inflammatory factors or protein/gene expression of cells. Yen et al. determined that Au nanoparticles (especially those of a smaller diameter) could upregulate the expression of the proinflammatory genes interleukin-1 (IL-1), interleukin-6 (IL-6), and tumor necrosis factor (TNF- $\alpha)$ [9].

Compared with in vitro toxicity assays, in vivo assays are more reflective of the mechanisms of nanomaterial toxicity in the bodies. The common types of in vivo nanomaterial toxicity include hematological toxicity, pulmonary toxicity, splenic toxicity, hepatotoxicity and nephrotoxicity [14]. Given the unique qualities of each type of nanomaterial, current research evaluating the toxicity of nanomaterials typically focuses on one aspect of the material properties at a time [14]. The toxicity of most nanomaterials designed for drug delivery systems is correlated with the way they contact with human body. For example, positively charged dendrimers and cationic macromolecules that are mainly restricted to the blood system have been found to interact with blood components, destabilize cell membranes, and induce cell lysis [15-17]. For nanomaterials interacting with human body with other ways, inflammatory changes are a useful means of evaluating toxicity. Poland et al. studied the effect of length on carbon nanotubes (CNT) toxicity via an intraperitoneal injection of MWCNT and observations of carcinogenic mechanisms in the abdominal cavity and the diaphragm [18]. In their study, Poland et al. observed that the longer length $(\geq 20 \mu \mathrm{m})$ CNT resulted in an inflammatory response within $24 \mathrm{~h}$, with consequent granuloma formation 7 days after injection. Moreover, additional damage to human bodies induced by the long-term accumulation of nanomaterials has gained increased attention in recent years. For example, Yang et al. studied the toxicity of intravenously injected SWCNTs in the major organs (e.g., liver, lung and spleen) in mice and demonstrated that no histopathological changes were observed in the liver or spleen; the SWCNTs were generally trapped in capillaries and formed aggregates of different sizes in the lung, with some inflammatory cells observed surrounding them [19].

Amphiphilic polymers like pegylated polyesters (PEGPLA, PEG-PLGA, PEG-PCL) are widely used as micelles in drug delivery system. Usually, the inherent physicochemical properties of polymers such as surface charge, hydrophobicity, size, shape, and aggregation tendencies are found to trigger different biological responses $[20,21]$. Generally, biodegradable polymers with electric neutrality, such as polyesters (PLGA), pegylated polyesters and so on, show low toxicity [22,23]. While, polycations are cytotoxic, inducing hemolysis and complement activation, and polyanions are less cytotoxic but still induce anticoagulant activity and cytokine release [24]. Currently, the main concern on toxicity of polymers is around their metabolism, immunotoxicity and complement activation [20] but there is no systematic safety evaluation has been established for polymers [22]. In this study, we compared the in vitro and in vivo toxicity of four types of micelles made from poly(ethylene glycol)-polyglycerolpoly(e-caprolactone) (PEG-PG-PCL), poly(ethyl ethylene phosphate)-co-poly( $\varepsilon$-caprolactone) (PEEP-PCL), poly(ethylene glycol)-poly( $\varepsilon$-caprolactone) (PEG-PCL) and poly (ethyleneglycol)-distearoyl-sn-glycero-phosphoethanolamine (PEG-DSPE) (Figure 1). PEG-PG-PCL, PEEP-PCL, PEGPCL and PEG-DSPE are all amphiphilic block copolymers. We chose these four types of polymers because they have similar hydrophilic or hydrophobic structure: for example, PEG-DSPE and PEG-PCL have the same hydrophilic segment. When they form into micelles, they have the same shell but a different core; PEEP-PCL and PEG-PCL have the same hydrophobic segment, and their cores are the same, but their shells are different when they form into micelles. Although the structure of PEG-PG-PCL is special, it also has similar shell and core with other three micelles.

PEG-PG-PCL is a novel amphiphilic linear-hyperbranched block copolymer that was successfully synthesized by the Zhong lab [25]. The special functionality of inner porosity and the dense surface of linear-dendritic block copolymers with a hybrid structure could possibly increase the 


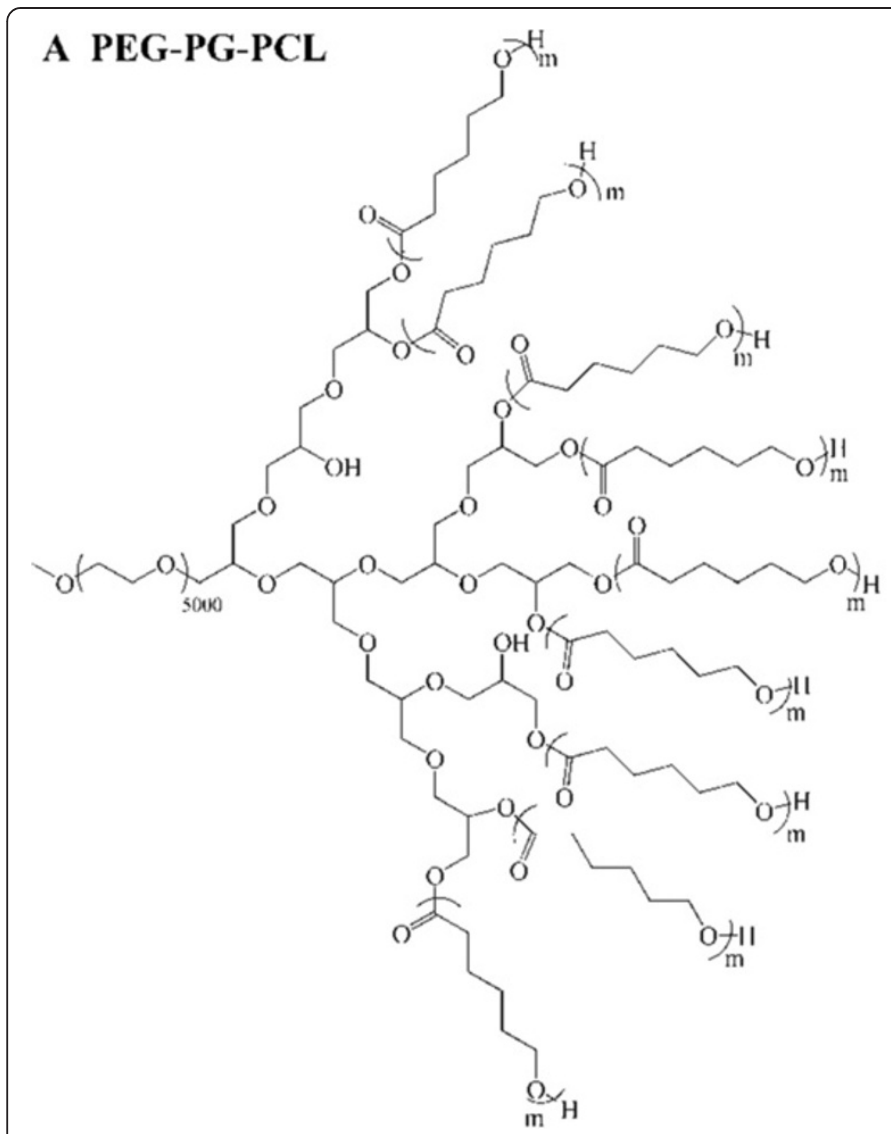

B PEEP-PCL<smiles>CCO[Pb](O)(OCCO)OCCCCCC(=O)OCc1ccccc1</smiles>

C PEG-PCL

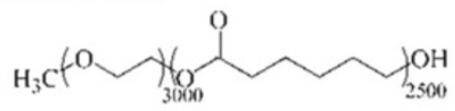

\section{PEG-DSPE}

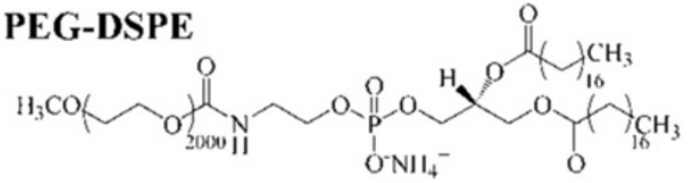

Figure 1 Chemical constitution of (A) $\mathrm{PEG}_{5000}-\mathrm{PG}_{300}-\mathrm{PCL}_{5700}$, (B) $\mathrm{PEEP} \mathrm{P}_{3600}-\mathrm{PCL}_{3800}$, (C) $\mathrm{PEG} 3000$ - $\mathrm{PCL}_{2500}$ and (D) $\mathrm{PEG}_{2000}-\mathrm{DSPE}_{800}$.

capacity and chemical flexibility of copolymer micelles [26]. When made into micelles, copolymers exhibit more sustained drug release behavior compared with PEG-PCL [25].

PEEP-PCL is another amphiphilic block copolymer recently synthesized by the Wang lab [27]. As polyphosphoesters are degradable and more structurally flexible for physicochemical property adjustments, hydrophilic polyphosphoesters may exhibit interesting properties for drug delivery system design [27]. PEEPPCL vesicles have been reportedly applied as biodegradable polymer vesicles for drug delivery, revealing that the doxorubicin-loaded vesicles can be successfully internalized by A549 cells to result in enhanced inhibition of A549 cell proliferation [28].

PEG-PCL and PEG-DSPE have been approved by the US Food and Drug Administration (FDA) and have been widely used in drug delivery systems. Li et al. prepared PEG-PCL nanoparticles from different copolymers, and through comprehensive evaluation, they concluded that the tetradrine-loaded nanoparticles exhibited more prominent antitumor effects than free tetradrine [29]. Zeng et al. loaded paclitaxel into PEG-DSPE nanoparticles and observed a higher relative bioavailability compared with the commercial product Taxol, indicating that these PEG-DSPE nanoparticles might serve as a potential sustained release system for poorly water-soluble agents [30].

However, apart from the potential applications of the four micelles prepared from PEG-PG-PCL, PEEP-PCL, PEG-PCL and PEG-DSPE in drug delivery, especially in tumor targeting delivery, the current understanding on the toxicity of these carriers is very limited [31]. A systemic evaluation of these nanomaterials is of great importance for further application in clinical therapeutic areas. Considering that micelles are mostly given via intravenous route, an umbilical vein cell line (Eahy.926) and a kind of macrophages (J774.A1) were used as cell models for in vitro toxicity evaluation. While, KM mice were used for in vivo toxicity study. Cell morphology and volume detection assays, an inflammatory factor detection assay, a reactive oxygen species (ROS) detection assay, a cell membrane fluidity detection assay, and cytotoxicity and apoptosis assays were conducted in the in vitro toxicity study. Complete blood counts, lymphocyte subset detection, detection of plasma inflammatory factors, and histological observations were performed in the in vivo toxicity study. Therefore, a comprehensive evaluation system that includes cell toxicity, immune 
toxicity, hematological toxicity and organs toxicity has been established.

\section{Results}

\section{Characterization of the micelles}

The sizes and zeta-potential of various micelles measured by Malvern Zetasizer Nano-ZS are shown in Table 1 and the size distribution is shown in Figure 2 (A-D). The particle sizes of the PEEP-PCL, PEG-PCL and PEG-DSPE micelles were 28.0, 43.0 and $17.4 \mathrm{~nm}$, respectively. While micelles prepared from PEG-PG-PCL was $173.4 \mathrm{~nm}$, obviously larger than other three micelles. The polydispersity index (PDI) of the micelles was all below 0.25 . The zeta potential of the micelles in PBS was slightly negative. The morphological characteristics of the four types of micelles observed by TEM are shown in Figure 2 (E-H). The micelles were spherical in shape, and their sizes were in accordance to the results of the dynamic light scattering measurements. The CMCs of the four polymers ranged from 0.7 to $2.7 \mu \mathrm{g} / \mathrm{ml}$, sufficiently low to maintain their micelle states during the experimental process.

\section{Cytotoxicity on J774.A1 cells Cell morphology}

Figure 3 shows the cell morphology of macrophages treated with various micelles at low $(5.28 \mu \mathrm{g} / \mathrm{ml})$, mid $(20.8 \mu \mathrm{g} / \mathrm{ml})$, and high $(83.3 \mu \mathrm{g} / \mathrm{ml})$ concentrations for $24 \mathrm{~h}$. The cells were all in round shape and appeared healthy. Cells treated with the four kinds of micelles did not exhibit significant differences from the control group. The average size of macrophages treated with various micelles at the concentration of $83.3 \mu \mathrm{g} / \mathrm{ml}$ for $24 \mathrm{~h}$ was further detected using flow cytometry. Higher values of FSC-Height represent a larger average cell volume. As Figure 4 demonstrates, after treatment with the micelles, the cells became larger in the PEG-PG-PCL group (439.2 \pm 18.6$)$ and PEEP-PCL group (444.2 \pm 10.2$)$, whereas the cell sizes in the PEG-DSPE group (367.4 \pm 12.2) and PEG-PCL group (380.8 \pm 8.1$)$ remained similar to the control group $(370.0 \pm 4.3)$.

\section{Inflammatory factor level}

Four inflammatory factors (IL-6, IL-10, IL-12p70 and IFN- $\gamma$ ) were not detected or were below the limit of detection $(20 \mathrm{pg} / \mathrm{ml})$ for all of the four micelles at $0.5,3$ and $24 \mathrm{~h}$. TNF and MCP-1 were not detected at $0.5 \mathrm{~h}$ (Figure 5). When the incubation time was increased, TNF and MCP-1 were detected; levels continued to increase with time. All of the micelles led to an obvious growth in MCP-1 compared with the control group treated with PBS at both $3 \mathrm{~h}$ and $24 \mathrm{~h}$ (excepting PEGDSPE micelles at $3 \mathrm{~h}$ ). Similar to their effects on cell size, PEG-PG-PCL and PEEP-PCL induced an increasing level of TNF $(119 \pm 15$ and $46 \pm 43 \mathrm{pg} / \mathrm{ml})$, whereas TNF was not detected or was below the detection limit in the other two groups at $24 \mathrm{~h}$.

\section{ROS level}

As shown in Figure 6, the ROS levels of cells treated with various micelles, which were assessed by the fluorescence intensity, were significantly higher than the PBS control. Among the four kinds of micelles, micelles made from PEG-PG-PCL and PEEP-PCL induced the highest and second-highest levels of ROS (550.5 \pm 15.6 , $453.6 \pm 2.1)$. The results exhibited similarity to the cell size study and the inflammatory factor detection. The fluorescence intensity values of PEG-PCL and PEGDSPE micelles were $440.4 \pm 8.3,435.9 \pm 10.6$, respectively, about $18 \%$ increase compared with PBS control $(372.5 \pm 6.5)$.

\section{Cytotoxicity study on Eahy.926 cells Cytotoxicity}

Figure 7 describes the survival rates of cells treated with micelles, which are expressed as the percentage of surviving cells compared with the cells treated with PBS. According to the data, the survival rates of cells treated with various concentrations of micelles were higher than 90\%, with the exception of PEG-DSPE (equal to $89.9 \pm$ 1.9\%). PEG-PCL in the high-concentration group exhibited the second-lowest survival rate, $93.3 \pm 1.2 \%$. Other groups exhibited no significant inhibition of Eahy.926 cells compared with the control group.

\section{Apoptosis}

To confirm the detection of apoptosis, dual staining with Annexin V-FITC and PI method was employed. This method permitted the quantification of early apoptosis, late apoptosis and necrosis. As shown in Figure 8, the number

Table 1 The characteristics of PEG-PG-PCL, PEEP-PCL, PEG-PCL and PEG-DSPE polymeric micelles $(m e a n \pm S D, n=3)$

\begin{tabular}{lccc}
\hline Preparations & Particle size $(\mathbf{n m})^{*}$ & PDI* $^{*}$ & Zeta potential* $(\mathbf{m V})$ \\
\hline PEG-PG-PCL & $173.4 \pm 5.3$ & $0.044 \pm 0.024$ & $-1.27 \pm 0.57$ \\
PEEP-PCL & $28.0 \pm 2.8$ & $0.131 \pm 0.102$ & $-4.75 \pm 0.74$ \\
PEG-PCL & $43.0 \pm 2.8$ & $0.225 \pm 0.052$ & $-1.21 \pm 0.13$ \\
PEG-DSPE & $17.4 \pm 0.8$ & $0.192 \pm 0.064[36]$ & $-2.49 \pm 0.54$ \\
\hline
\end{tabular}

*in phosphate-buffered saline (PBS, pH 7.4). 


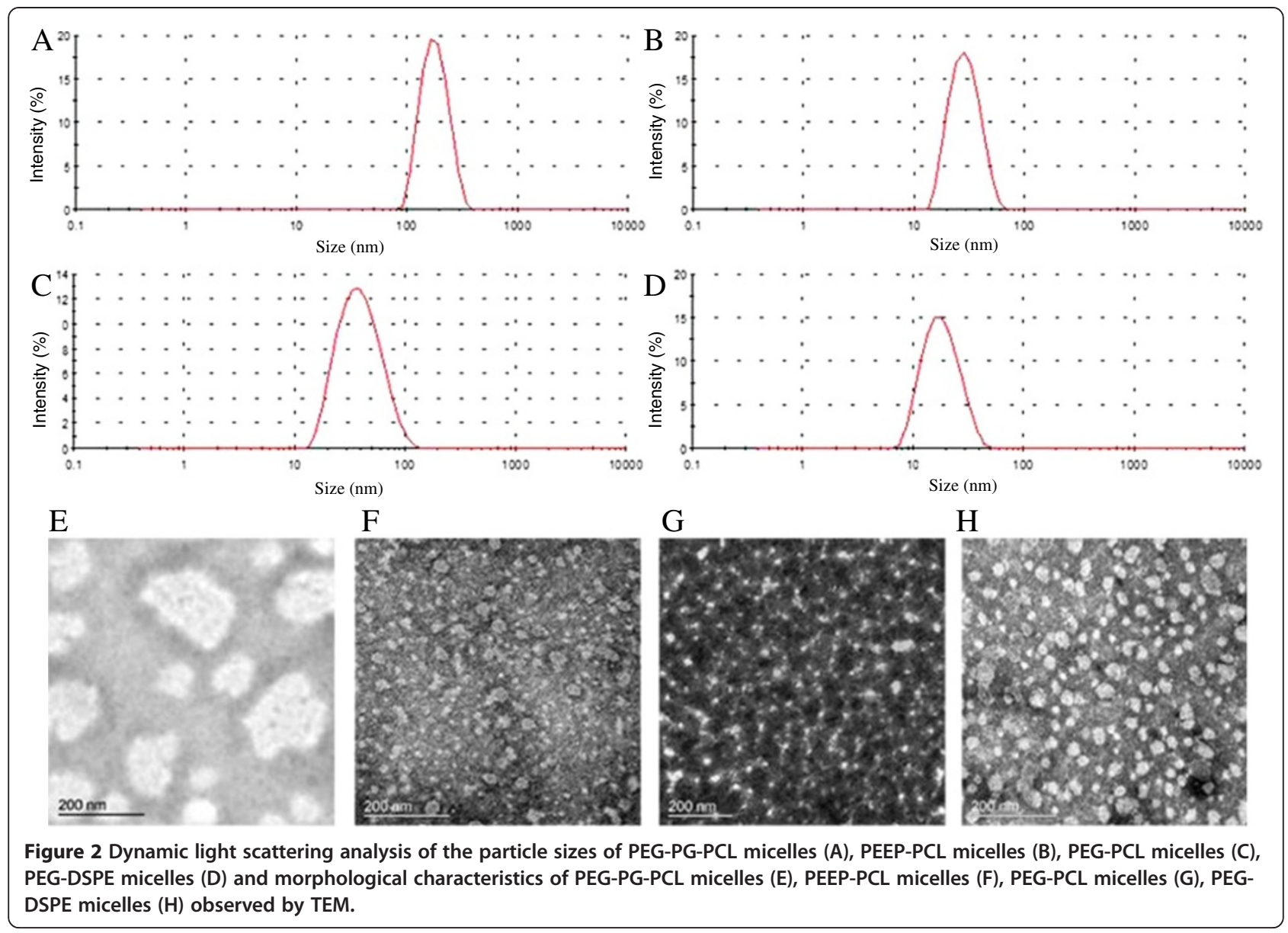

of cells undergoing early apoptosis in each group was below $5 \%$ and exhibited no differences from the PBS control. Similar to the cytotoxicity results, the PEG-DSPE group exhibited the highest rate of late apoptotic and necrotic cells $(28.3 \pm 4.3 \%)$, which was significantly different from the PBS control $(10.2 \pm 1.1 \%)$. In the other three groups, no significant differences were observed.

\section{Cell membrane fluidity}

To investigate in detail whether the micelles made from the dual-affinity nanomaterials could influence cell membrane fluidity, we analyzed the cell membrane fluidity by $\mathrm{DPH}$ assay. DPH is a fluorescent probe commonly used to estimate the bulk of apparent microviscosity of membranes. As the quantum yield of DPH is constant between the various membrane systems, a comparison of apparent membrane microviscosity values can be made using polarization values; a higher polarization value indicates a less fluid cell state. Figure 9 shows the results of this test. Although PEEP-PCL exhibited a higher average $\mathrm{P}$, no significant difference was observed between PEEP-PCL and PBS. For the other groups, the results were similar, indicating that the four kinds of micelles at the concentration $83.3 \mu \mathrm{g} / \mathrm{ml}$ did not influence the cell membrane fluidity of Eahy.926 cells within $24 \mathrm{~h}$.

\section{Toxicity study on KM mice Complete blood count}

As shown in Figure 10, none of the micelles induced a significant difference in HGB and RBC counts. The PEG-PCL group, which affected the most factors of the complete blood count, caused three factors to decrease: WBC $(8.0 \pm 2.5$ versus $12.3 \pm 2.7, p<0.01)$, MID $(1.0 \pm 0.3$ versus $1.4 \pm 0.3, p$ $<0.01)$ and LYM $(6.1 \pm 2.1$ versus 9.4 $\pm 2.4, p<0.01)$. Compared to the saline $(1.3 \pm 0.7)$ control group, PEG-DSPE $(2.1 \pm 0.8, p<0.01$ versus saline) and PEEP-PCL $(2.0 \pm 0.6$, $p<0.01$ versus saline) both led to a significant increase in GRN counts. Moreover, the PLT counts of the PEG-PG-PCL $(512.4 \pm 129.3, p<0.01$ versus saline) group were significantly higher than the saline $(331.6 \pm 49.7)$ control group.

\section{Lymphocyte subsets}

Lymphocyte subsets of the peripheral blood were investigated, and the results are shown in Figure 11. According to the results, $\mathrm{CD}^{+}$cells and $\mathrm{CD} 19^{+}$cell counts exhibited no significant differences in the four micelle groups compared with the saline group. However, the proportion of $\mathrm{CD}^{+}$ cells $(47.1 \pm 3.9, p<0.01)$ in the blood of mice treated with PEEP-PCL micelles was higher than that in mice treated with saline (37.9 \pm 6.8$)$. 

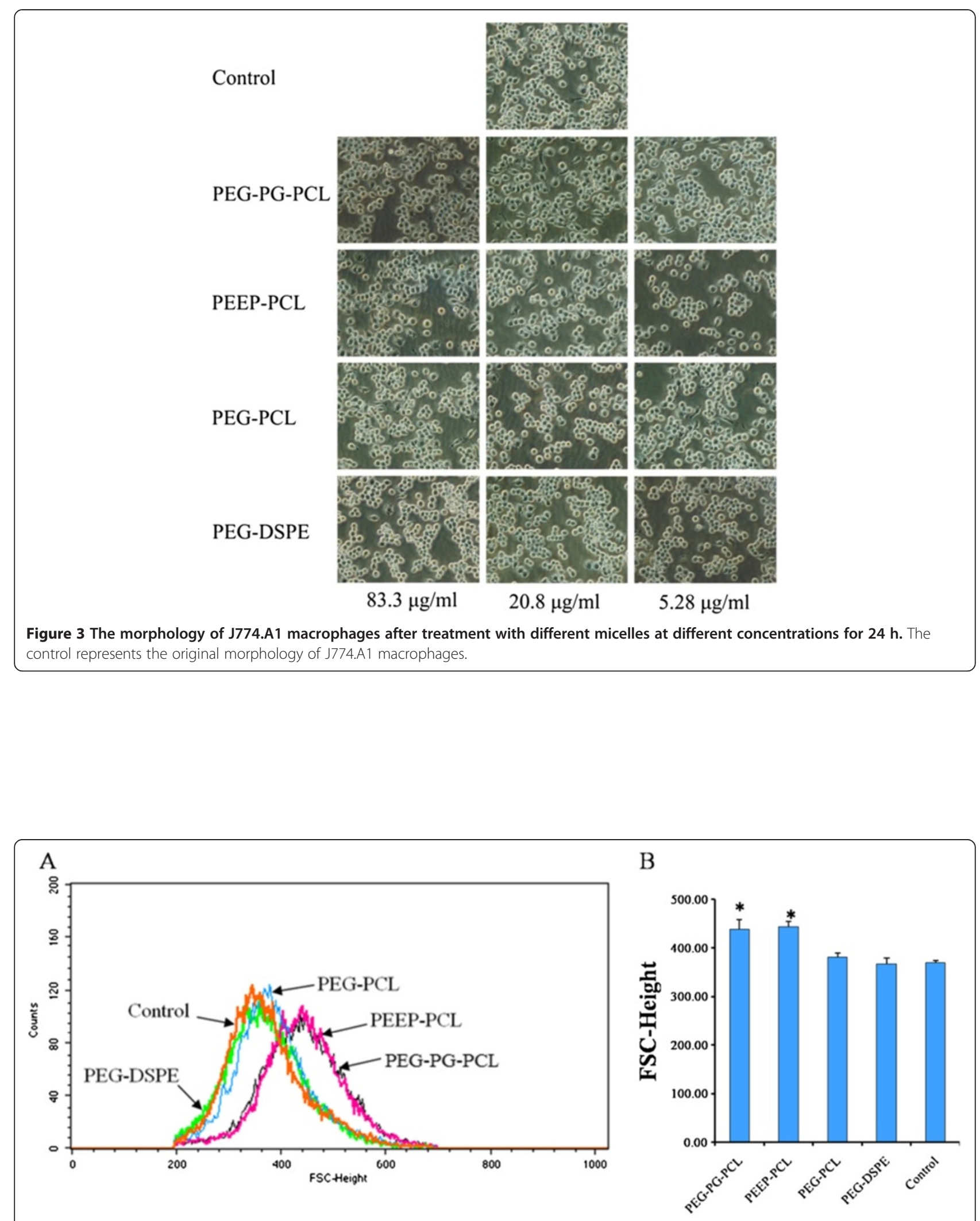

Figure 4 Flow cytometric measurements of J774.A1 cell volumes treated with different micelles at $83.3 \mu \mathrm{g} / \mathrm{ml}$ for $24 \mathrm{~h}$. PBS-treated cells served as control. The average cell volume was indicated by the value of FSC-Height. (A) Flow cytometric histogram; (B) Average value of FSC-Height $(n=3$, mean $\pm S D) .{ }^{*} p<0.01$ vs. PBS control. 


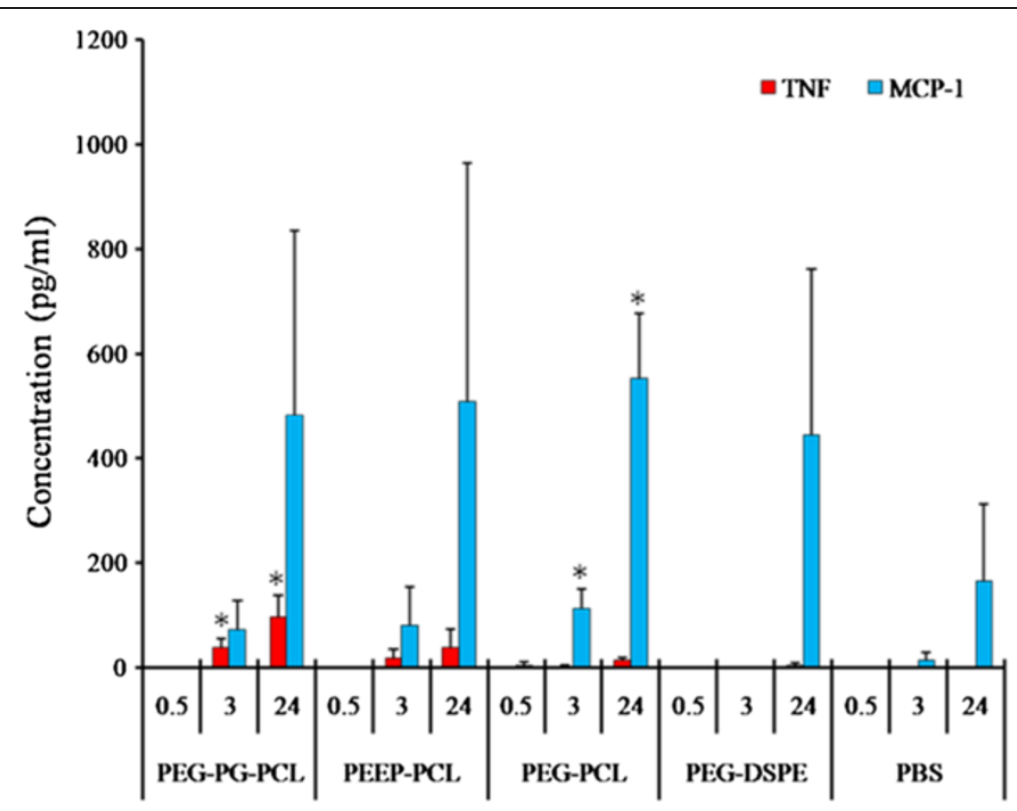

Figure 5 Inflammatory factor levels in the medium of J774.A1 cells treated with micelles at different time points (0.5, 3 and 24 h). PBS-treated cells served as controls. The results are given as the mean $\pm \mathrm{SD}, \mathrm{n}=3 .{ }^{*} p<0.05 \mathrm{vs}$. PBS control.

\section{Inflammatory factors in plasma}

The effect of the micelles on the levels of inflammatory mediators in the plasmic of mice was detected using the CBA technique. Four inflammatory factors (IL-6, IL-10, IL-12p70 and IFN- $\gamma$ ) were not detected or were below the limit of detection $(20 \mathrm{pg} / \mathrm{ml})$. TNF and MCP-1 were detected, as shown in Figure 12. No significant differences were observed between any group and the saline group.

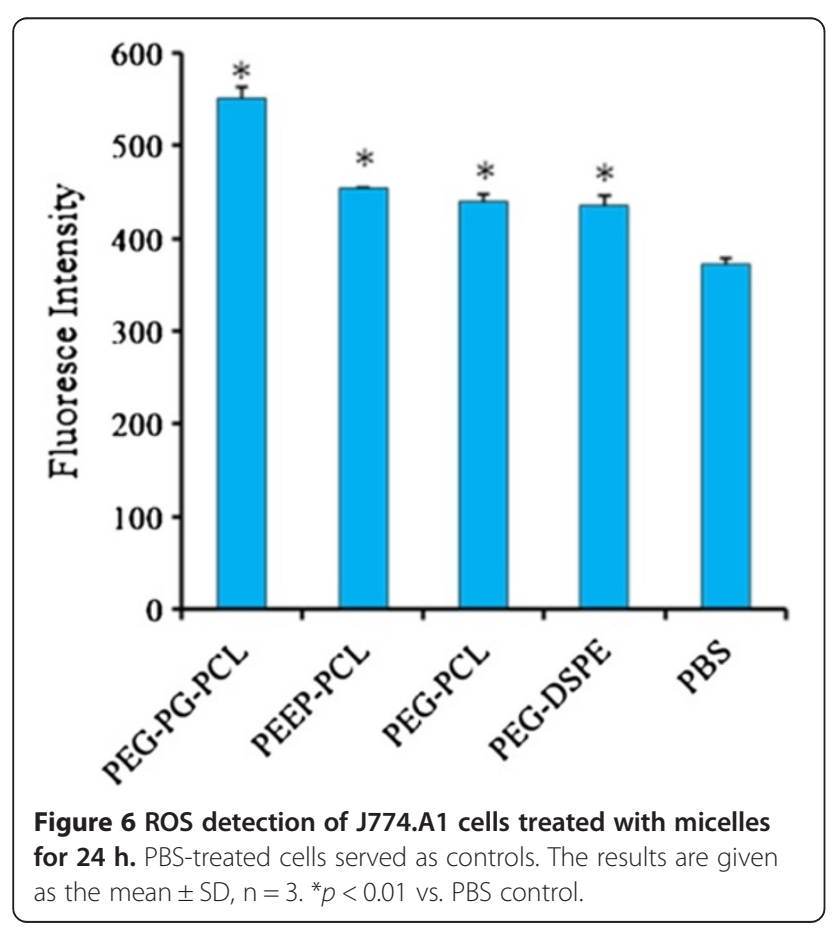

\section{Histological observations}

Histological observations were conducted to determine the organic damage induced by micelles (Figure 13). No clear organic damage was observed in the histological study among all of the exposed groups. However, the alveolar septae were widened, exhibiting blood vessel dilatation and

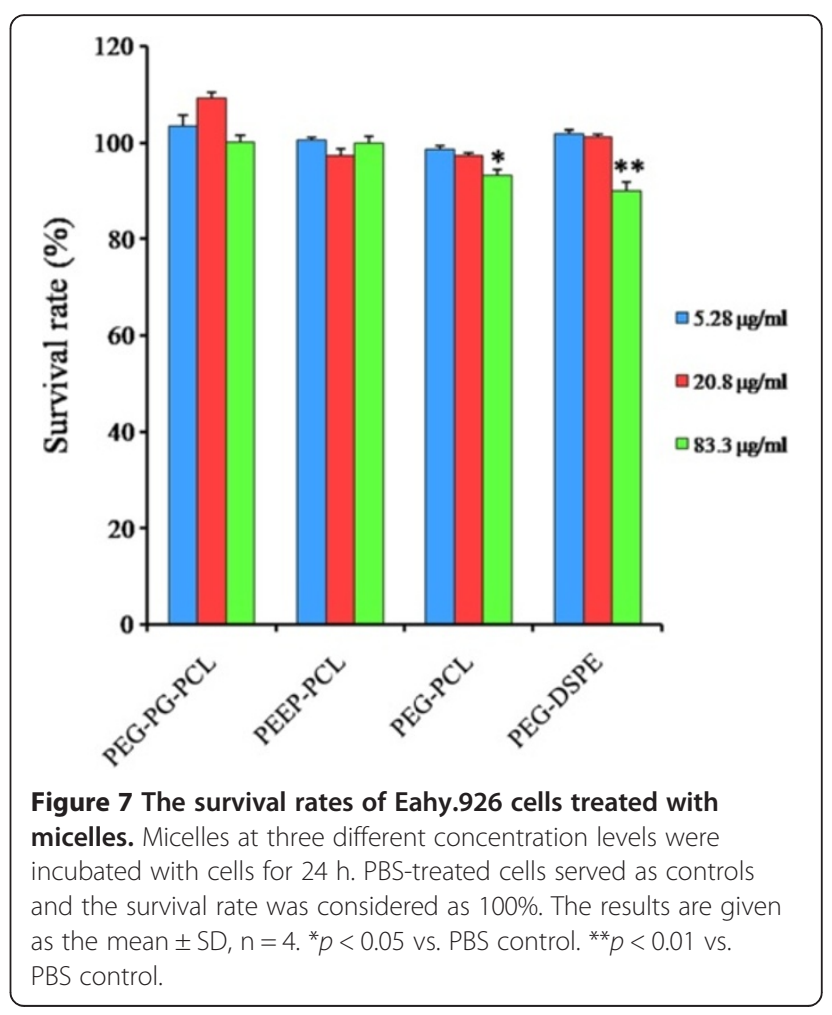



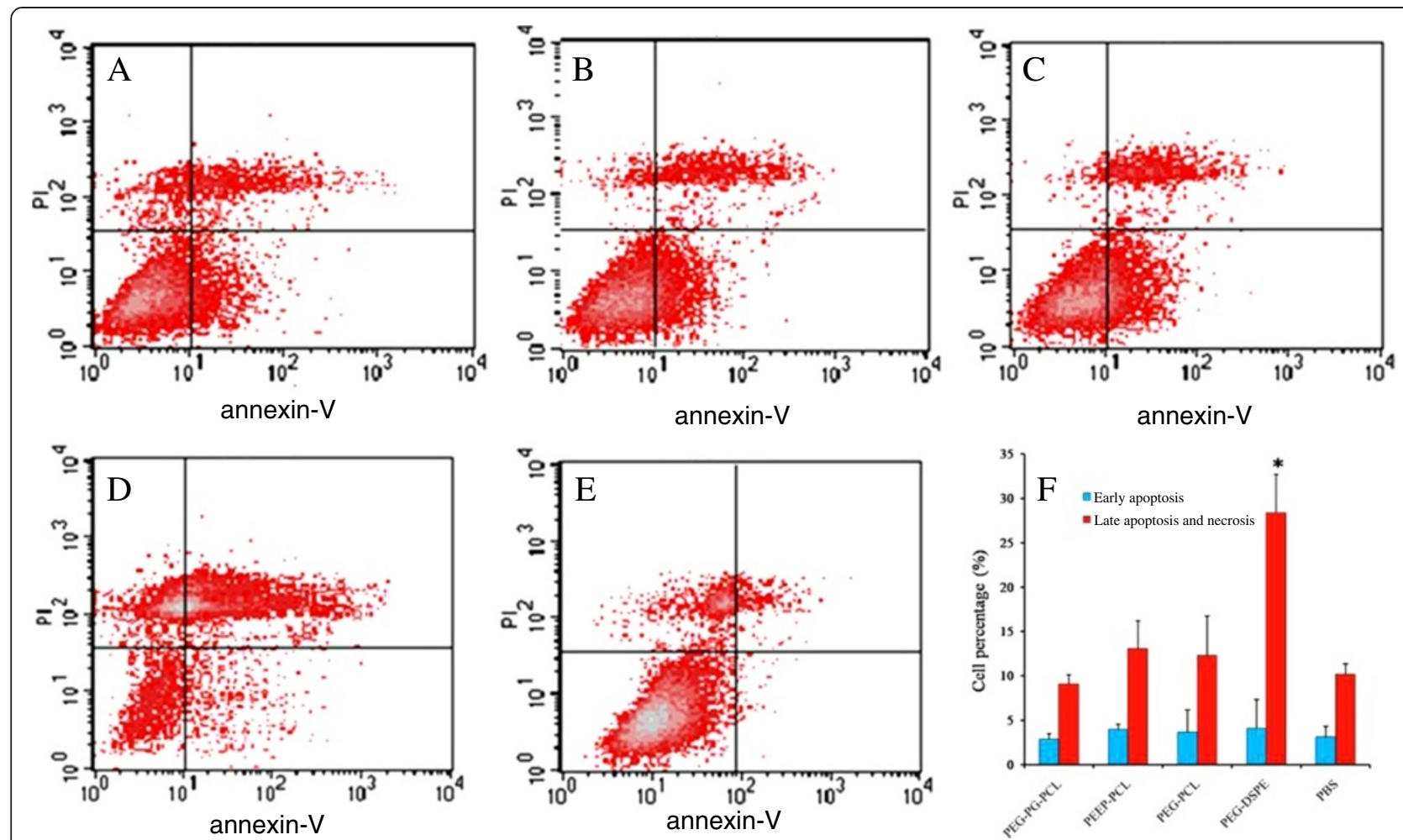

Figure 8 Apoptosis of Eahy.926 cells induced by PEG-PG-PCL (A), PEEP-PCL (B), PEG-PCL (C), PEG-DSPE (D) and PBS (E) after 24 h. (F) was the result of apoptotic cell percentage of triplicate tests reported as mean \pm SD. ${ }^{*} p<0.01$ vs. PBS control.

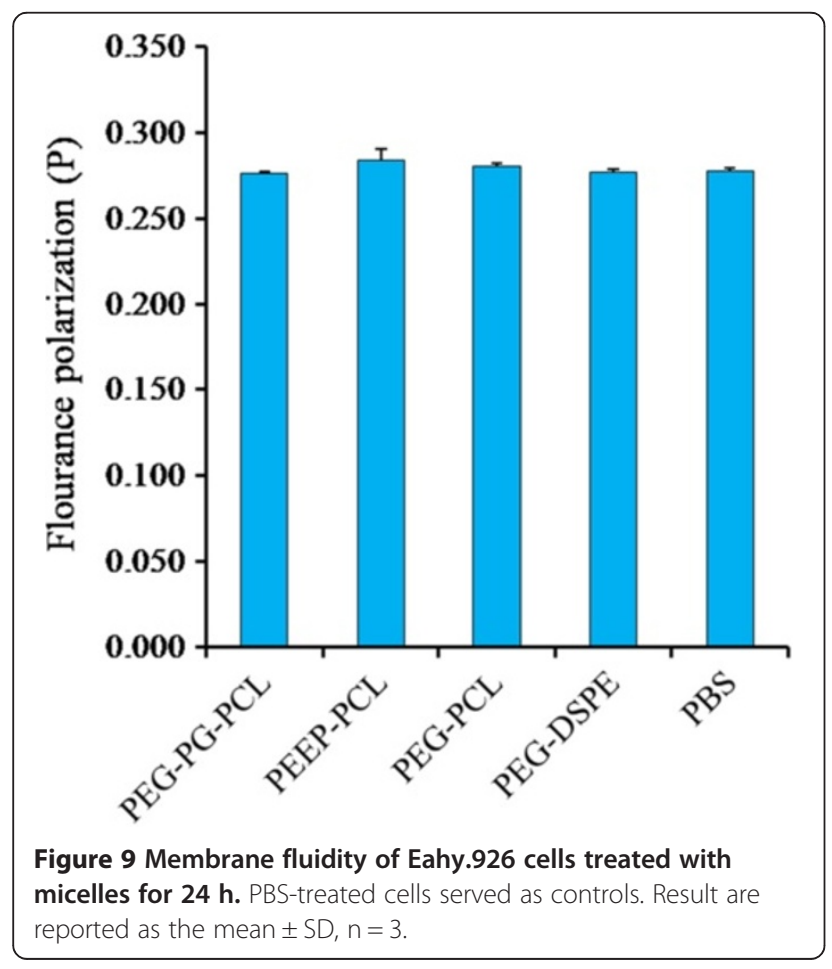

congestion in parts of the lung samples of the PEEP-PCL group and control group; the cytoplasm was widened, lightly stained and highly loose in the liver sample in PEGPCL group. The organic changes did not represent serious damage and could be a random phenomenon; the control group also exhibited similar changes. The histological observations suggest that these four kinds of micelles cause no significant organic damage but may induce some local changes in certain parts of the organs.

\section{Discussion}

PEG-PG-PCL, PEEP-PCL, PEG-PCL and PEG-DSPE micelles are commonly used for novel nano-preparations. As shown in Figure 1, PEG-PG-PCL has a unique structure of linear-hyperbranched blocks with many arms, whereas PEEP-PCL, PEG-PCL and PEG-DSPE are long chain polymers. Despite the structural differences among these nanomaterials, they all exhibit amphiphilic properties, making it possible for them to form micelles and load drugs. Among these four kinds of micelles, the size of the PEG-PG-PCL micelles was larger than the other three types of micelles; however, the zeta-potentials of these micelles in PBS ( $\mathrm{pH}$ 7.4) did not differ. The CMCs were all below $3 \mu \mathrm{g} / \mathrm{ml}$, and the micelle concentrations in our investigation were higher than $5 \mu \mathrm{g} / \mathrm{ml}$ (even in vivo, the micelle concentration was approximately 


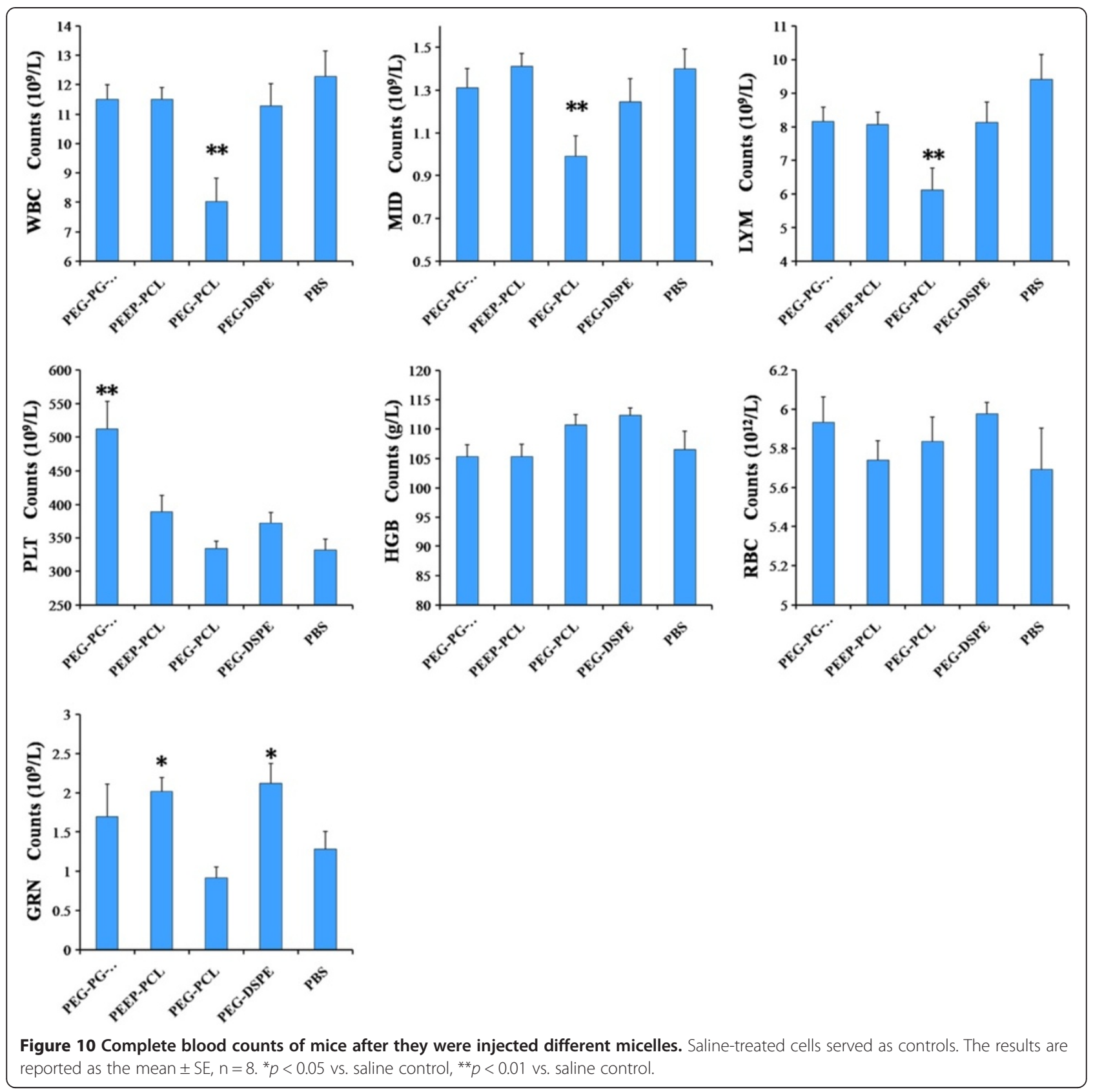

$80 \mu \mathrm{g} / \mathrm{ml}$ ), indicating the micelles could maintain their micellar state in the present study in vitro and in vivo.

Two cell lines, J774.A1 and Eahy.926, were used in this study. J774.A1 cells are mononuclear macrophages. The cell line is used as an immune cell model to study the immune responses after stimulation by the micelles. Eahy.926 cells are vascular endothelial cells and are used as a cellular model of the vascular wall. Eahy.926 cells are used to study the toxicity of nanomaterials on the vascular endothelium $[32,33]$. The reason for the choice of these two cells lies in the application of these nanomaterials in drug delivery. After the micelles are administered intravenously, they (or their original materials and degradation products) typically persist in the blood circulation and have direct access to the blood cells (including immune cells, such as LYM, WBC and macrophages) and vascular endothelial cells.

Macrophages are very sensitive cells in the blood and could respond rapidly to acute nanoparticle toxicity. Normally, macrophages exist in a resting state. When they are stimulated to become active, macrophages grow in volume and are able to engulf foreign antigens and secrete cytokines [34]. As we have demonstrated, J774.A1 cells treated with the micelles exhibited no significant 


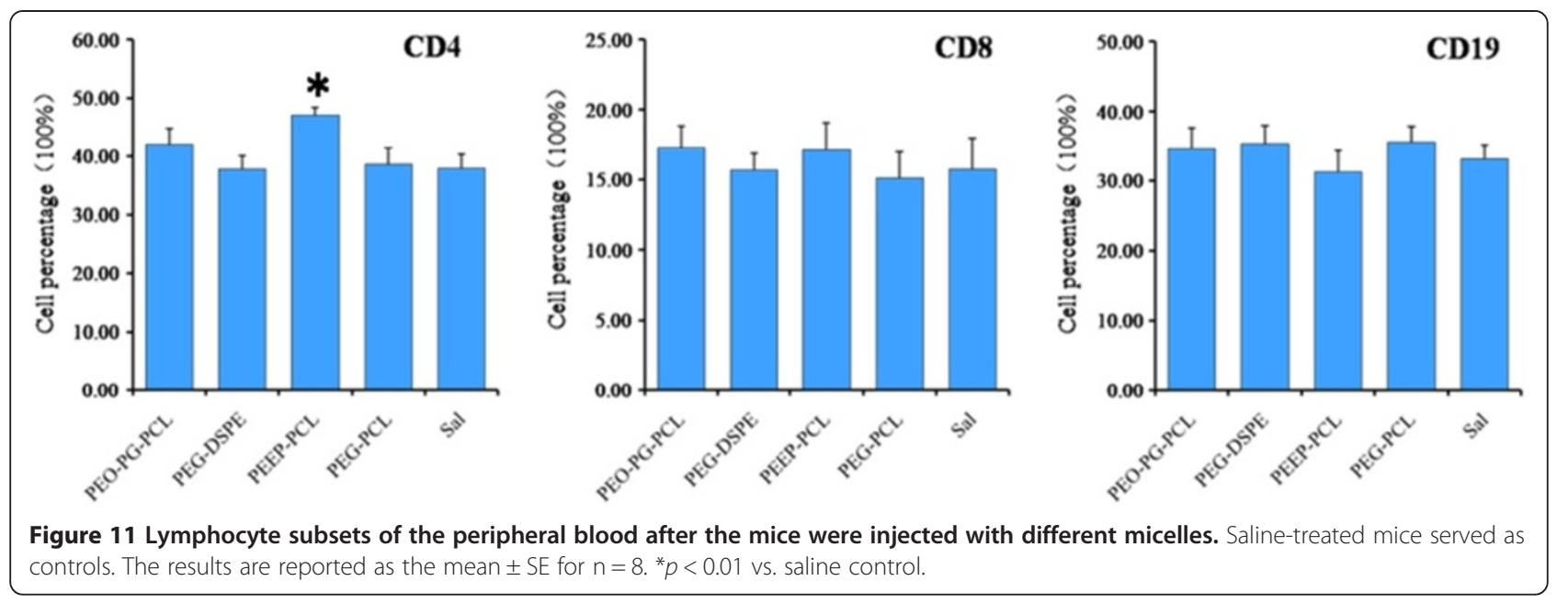

change in shape (Figure 3); however, upon further investigation, we observed an increase in J774.A1 cell size in the PEG-PG-PCL and PEEP-PCL groups (Figure 4). Moreover, PEG-PG-PCL and PEEP-PCL micelles induced TNF, and all four kinds of micelles induced an increase in MCP-1 (Figure 5), indicating that the stimulation process was initiated by the contact between micelles and J774.A1 cells.

During (or after) the stimulation process, protein and ATP content in macrophages increases, oxygen consumption increases significantly, cellular enzymatic activity increases, and the generation of ROS increases [34]. ROS levels significantly increased after treatment

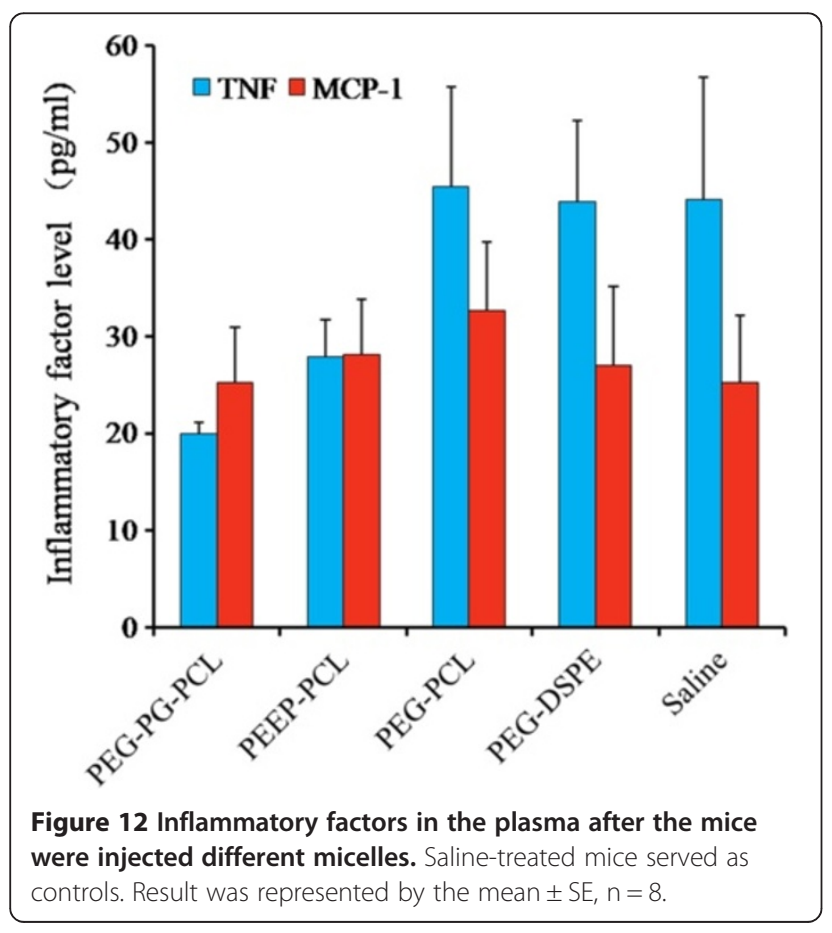

with the micelles; PEG-PG-PCL micelles induced the highest level of ROS, and PEEP-PCL micelles induced the second-highest levels (Figure 6). These results suggested that treatment with micelles might elicit an immunological response, resulting from the increasing of ROS levels.

Among all of the micelles, PEG-PG-PCL micelles, followed by PEEP-PCL micelles, most strongly stimulated J774.A1 cells. The reason for difference might lie in the size difference of the micelles and the structure difference of these nanomaterials; phagocytosis generally occurs when particle sizes are larger than $100 \mathrm{~nm}$ [35]. The size of the PEG-PG-PCL micelles was $173 \mathrm{~nm}$. Thus, J774.A1 cells may have recognized the PEG-PGPCL micelles and activated. However, there is no clear reason to explain the phenomenon in PEEP-PCL micelles. We speculated that the interaction might be related to the negatively charge of PEEP-PCL micelles. PEEP, with many phosphoesters, deduced the micelles negatively charged in aqueous solution $(-14.4 \mathrm{mV})$, although it was nearly neutral $(-4.75 \mathrm{mV})$ when added to PBS due to buffer action. As it is reported, negatively charged nanoaprticles can show stronger interaction with cells through nonspecific binding and clustering of the particles on cationic sites on the plasma membrane (that are relatively scarcer than negatively charged domains) compared to nanoparticles with neutral surfaces [23]. In another study on how hydrophilic and hydrophobic structures influence micelle transport in epithelial MDCK cells, PEEP-PCL micelles indeed exhibited unique behavior in terms of endocytosis, exocytosis, organelles colocalization and transcytosis. For example, PEEP-PCL micelles were easier to locate in lysosomes than endoplasmic reticulum in the first ten minutes, while PEG-PCL micelles were concentrated more in endoplasmic reticulum in the first 10 minutes [36].

In the study on Eahy.926 cells, cytotoxicity and apoptosis analyses were conducted. Cytotoxicity and apoptosis 


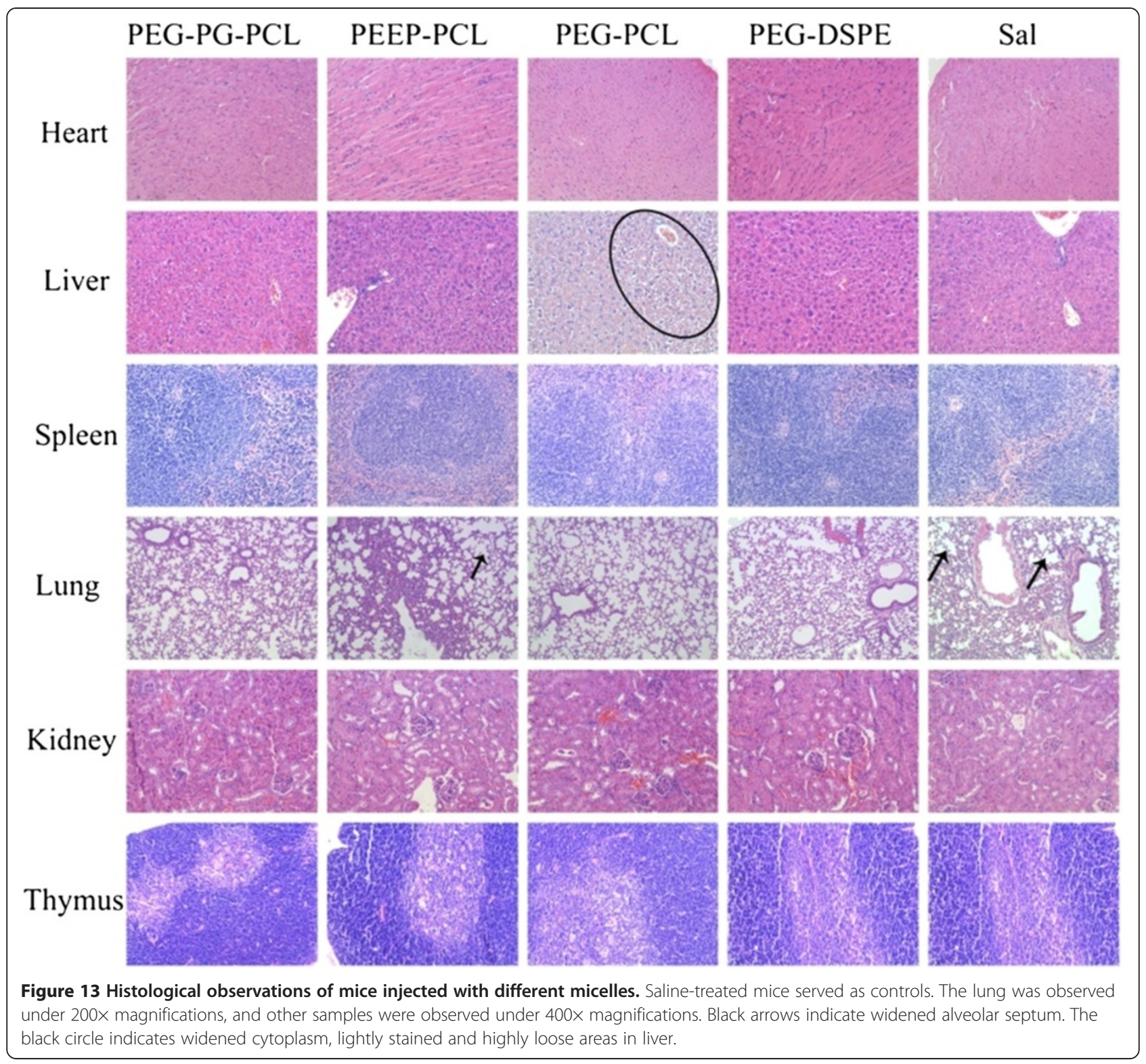

analyses are typically used to detect the direct damage of nanocarriers or their degradation products on vascular endothelial cells. The results of the cytotoxicity and apoptosis revealed that among these four kinds of micelles, PEGDSPE micelles $(83.3 \mu \mathrm{g} / \mathrm{ml})$ significantly inhibited the growth of Eahy.926 cells (Figure 7) and increased the percentage of late apoptotic and necrotic cells (Figure 8). Apoptosis is a form of programmed cell death that occurs through the activation of cell-intrinsic suicide machinery [37]. The increasing percentage of late apoptotic and necrotic cells indicates that PEG-DSPE micelles may trigger apoptosis, leading to the inhibition of cell growth that was observed. We considered that the higher cytotoxicity and apoptosis of PEG-DSPE micelles might result from the higher cellular uptake ability of PEG-DSPE micelles. In our previous study, it was shown that the uptake of the three micelles ranked as PEG-DSPE $>$ PEG-PCL $>$ PEEP-PCL [36]. We considered that as a type of phospholipid with a similar structure to the cell membrane, DSPE had good affinity with cell membrane and deduced higher uptake.

Monitoring cell membrane fluidity is based on the principle that materials exhibit a fat-soluble structure that can insert into the cell membrane and affect its properties. However, in our research, there was no evidence demonstrating that these micelles had any effects on the membrane fluidity of Eahy.926 cells at the given concentration (Figure 9). It is possible that the contact process between the micelles and cells was too long, 
allowing the cell membrane sufficient time to recover to its origin state, and the interaction between the cell membrane and the micelle process could not be observed.

There were certain differences in the influence of micelles on J774.A1 cells and Eahy.926 cells. J774.A1 cells were stimulated largely by PEG-PG-PCL and PEEP-PCL micelles, but Eahy.926 cells were influenced mainly by PEG-DSPE micelles. We considered the reason for this difference might be associated with the different characteristics of J774.A1 and Eahy.926 cells. As Lewinski et al. reported, from the toxicity study on the effect of C60 exposure under various experimental conditions with different cell lines, the results indeed were related to cell type [38]. J774.A1 cells are of macrophages that can rapidly respond to the environmental changes by secreting various factors. In contrast, Eahy.926 cells are human endothelial cells that exhibit different functions in the human body. As they have unique functions, different reactions to similar stimulations are reasonable.

As we have observed certain physical and chemical changes in the cell models above, it remains to be understood whether these cellular changes occur and cause pathophysiological changes in vivo? To answer this question, we conducted a toxicity study in KM mice. There were no obvious body weight and behavior changes post-exposure for all the micelle groups and control (data not shown). Generally, when micelles are injected into vessels of mice, they immediately contact the blood cells and may be delivered to every possible organ and enter cells [33]. We therefore monitored the changes in complete blood cell counts, lymphocyte subset analysis, plasma inflammatory cytokines and changes in target organs, such as the heart, liver, spleen, lung, kidney and thymus. After multiple doses, the micelles of these nanomaterials caused certain changes in blood cells; for example, PEG-PCL micelles decreased the level of WBC, LYM and MID, which are all immune cells that may influence the levels of inflammatory cytokines. PEG-DSPE and PEEP-PCL increased the level of GRN, another type of immune cells, whereas PEG-PG-PCL increased the number of PLT (Figure 10), which may induce hemorrhage, thrombosis or splenomegaly. In the lymphocyte subpopulation analysis, PEEP-PCL induce some increase in the $\mathrm{CD}^{+}$lymphocyte subpopulation (Figure 11), indicating that PEEP-PCL micelles could stimulate the immune system.

As a result of changes in the circulatory system, other changes in inflammatory factors and organs could follow. However, in our research, rapid changes in inflammatory factors and pathological target organs changes were not observed. One possible explanation might be the time point at which we detected inflammation factors, $24 \mathrm{~h}$ after injection, which was long enough for the micelles and inflammation factors to be cleared by the circulation system of mice. Another reason might be that the micelles did stimulate the blood cells and immune cells; however, the stimulation was not strong enough to cause obvious changes in our detection. Alternatively, the micelles of these nanomaterials in circulatory system may have stimulated lymphocytes of blood, which led to cellular stress and subsequent differentiation; this defense system to avoid a further damage on target organs, and the short-term secretion effect of inflammatory cell stress was eliminated after $24 \mathrm{~h}$.

When these in vitro (on cells) and in vivo (on mice) results were compared comprehensively, we found that the toxicity in vivo was not as significant as that in vitro. There are several possible reasons: (1) The micelles in vivo exist mainly in the blood system, which is a dynamic environment, whereas the in vitro studies are performed in a relatively static environment, thereby providing more chances for micelles to contact cells. (2) The body's innate ability to self-regulate is much more prevalent than regulation in cultured cells.

\section{Conclusions}

In this study we prepared PEG-PG-PCL, PEEP-PCL, PEG-PCL and PEG-DSPE micelles and compared their nanotoxicity on J774.A1 cells, Eahy.926 cells and mice. It was indicated that all micelle systems induced a change in inflammatory factors, potentially as a result of the increased level of ROS. PEG-PG-PCL micelles and PEEP-PCL micelles led to an increase in cell volume. This phenomenon likely correlated with the size of PEGPG-PCL micelles and the polyphosphoester structure in PEEP-PCL. Besides, PEG-DSPE micelles inhibited the growth of Eahy.926 cells by inducing apoptosis. No evidence was found for cell membrane changes after treatment with these micelles. Likely due to the direct injection into veins, these nanocarriers were found to influence blood components differently. However, these changes in the blood did not induce significant alterations in inflammatory factors and pathology of major mouse organs. The difference between the in vitro and in vivo results indicates that the in vitro toxicity may not occur in vivo, probably because the animal body can protect against certain toxicities. Additionally, there may be other toxicity-related reactions found in vivo that were not observed in vitro due to the unknown reasons. Because there is currently no standard for nanotoxicity, it is difficult for us to conclude whether the observed changes are serious or negligible. In general, it is demonstrated that the micelle systems tested here show diverse nanotoxicity correlated with their structures and their biosafety is different in different cell model. This study will certainly provide more scientific understandings on the nanotoxicity of amphiphilic polymeric micelles. 


\section{Materials and methods Materials}

Poly(ethylene glycol)-polyglycerol-poly( $\varepsilon$-caprolactone) (PEG ${ }_{5000}-\mathrm{PG}_{300}-\mathrm{PCL}_{5700}$, Mw 11000) was synthesized by the Department of Chemistry, Wuhan University (Wuhan, Hubei, China). Poly(ethyl ethylene phosphate)co-poly(e-caprolactone) (PEEP $\left.3600-\mathrm{PCL}_{3800}, \mathrm{Mw} 7400\right)$ was synthesized by the National Laboratory for Physical Sciences at the Microscale and School of Life Sciences, University of Science and Technology of China (Hefei, Anhui, China). Poly (ethylene glycol)-poly ( $\varepsilon$-caprolactone) ( $\mathrm{PEG}_{3000}-\mathrm{PCL}_{2500}$, Mw 5500) was purchased from Advanced Polymer Materials, Inc. (Montreal, QC, Canada). Poly(ethyleneglycol)-distearoyl-sn-glycero-phosphoethanolamine $\left(\mathrm{PEG}_{2000}-\mathrm{DSPE}_{800}, \mathrm{Mw} 2800\right)$ was obtained from the NOF Corporation (Japan). Cytometric bead array (CBA) mouse inflammation kit was purchased from BD Biosciences (San Jose, CA, US). Cell counting kit-8 (CCK-8) was supplied by Dojindo (Tabaru, Mashikimachi, kamimashiki gun Kumamoto, Japan). 1,6-diphenyl-1,3,5hexatriene (DPH) and $2^{\prime}, 7^{\prime}$-dichlorofluorescin diacetate (DCFH-DA) was purchased from Sigma (St. Louis, MO). Annexin V-fluorescein-isothiocyanate (Annexin V-FITC) and propidium iodide (PI) was purchased from Biomiga (Santiago, US). Antibodies CD19-FITC, CD4-FITC, CD8a-phycoerythrin (CD8a-PE) and CD3e-peridinin chlorophyll protein (CD3e-PerCP) were purchased from BD Biosciences (San Jose, CA, US).

\section{Cells}

J774.A1 murine macrophages (from the Institute of Basic Medical Science, China Academic Medical Science, Beijing, China) and Eahy.926 human umbilical vein cell line (from the Type Culture Collection of the Chinese Academy of Sciences, Shanghai, China) were cultured in high-glucose Dulbecco's modified Eagle's medium (DMEM; Gibco, Carlsbad, CA, USA) containing 10\% fetal calf serum, $1 \%$ penicillin- streptomycinamphotericin B solution. The cells were cultured in an incubator at $37^{\circ} \mathrm{C}$ in an atmosphere of $5 \% \mathrm{CO}_{2} / 95 \%$ air and $99 \%$ relative humidity and passaged twice a week.

\section{Animals}

Male KM mice (18-22 g) were obtained from Peking University Animal Center, Beijing, China. They were housed in plastic cages (4 mice/cage) and kept on a $12 \mathrm{~h}$ light/dark cycle. Food and water were provided ad libitum. All animal experiments were performed in compliance with the institutional ethics committee regulations and guidelines on animal welfare (Animal Care and Use Program Guidelines of Peking University).

\section{Preparation and characterization of micelles Preparation of PEG-PG-PCL and PEEP-PCL micelles}

PEG-PG-PCL and PEEP-PCL micelles were prepared using a solvent dispersing method. Briefly, $4 \mathrm{ml}$ deionized water was slowly dropped into $1 \mathrm{ml}$ stirring acetonitrile containing $5 \mathrm{mg}$ PEG-PG-PCL or $5 \mathrm{mg}$ PEEP-PCL. Afterward, the mixture was evaporated to approximately $3 \mathrm{ml}$ in a $37^{\circ} \mathrm{C}$ water bath. Next, the same volume of $2 \times$ phosphate-buffered saline (PBS) was added to the mixture, and a PEG-PG-PCL or PEEP-PCL micelle solution with PBS (pH 7.4) was obtained.

\section{Preparation of PEG-DSPE and PEG-PCL micelles}

To prepare PEG-DSPE and PEG-PCL micelles, the thinfilm dispersion method was used [39]. Briefly, $5 \mathrm{mg}$ PEG-DSPE or PEG-PCL was dissolved in $1 \mathrm{ml}$ acetonitrile, and subsequently evaporated under a vacuum until a thin lipid film formed. The lipid film was hydrated with $1 \mathrm{ml} \mathrm{PBS} \mathrm{(pH} \mathrm{7.4)} \mathrm{at} 25^{\circ} \mathrm{C}$ for PEG-DSPE micelles and at $60^{\circ} \mathrm{C}$ under a sonicator for PEG-PCL micelles. Lastly, $5 \mathrm{ml}$ additional PBS ( $\mathrm{pH}$ 7.4) was added to the mixture, and PEG-DSPE or PEG-PCL micelles were prepared.

\section{Characterization of micelles}

The particle size and Zeta potential were determined by dynamic light scattering (Malvern Zetasizer Nano-ZS, Malven Instruments, Malven, UK). The dispersion medium used in characterization of the micelles was PBS ( $\mathrm{pH}$ 7.4). The intensity was used for calculating the size of the micelles. The morphology of the micelles was characterized by transmission electronic microscopy (TEM, JEOL, JEM-200CX, Japan). The critical micelle concentration $(\mathrm{CMC})$ of different polymers was determined by pyrene fluorescence probe spectrometry [36].

\section{Toxicity study on J774.A1 cells Cell culture}

J774.A1 cells were seeded in 6-well culture plates at an initial density of $2 \times 10^{5}$ cells per well. After $24 \mathrm{~h}$ of culture, the medium was changed to fresh medium containing different micelles at the reported concentrations, and the cells were cultured for another predetermined time. Cells treated with PBS were used as controls.

\section{Cell morphology and volume detection}

For cell morphology visualization, the cells were treated with micelles at different concentrations (5.28, 20.8 and $83.3 \mu \mathrm{g} / \mathrm{ml}$ ) for $24 \mathrm{~h}$ and were observed at $200 \times$ magnifications with a Provis microscope (Olympus) [9].

For cell volume detection, the cells were treated with micelles at $83.3 \mu \mathrm{g} / \mathrm{ml}$ for $24 \mathrm{~h}$. Next, the cells were rinsed three times to remove residual micelles in the 
medium before the cells were detached by trypsin. Then, the cells were centrifuged and resuspended in $400 \mu \mathrm{l}$ PBS. The number and average size of the cells were determined by a flow cytometer (Beckman Coulter Reagents, USA).

\section{Detection of inflammatory factors}

To detect inflammatory factors, we used a technique known as cytometric bead array (CBA) (San Jose, CA, US) [40]. Capture beads bound to antibodies of six different fluorescence intensities were used to detect six inflammatory factors (interleukin-6 (IL-6), interleukin-10 (IL-10), interferon- $\gamma$ (IFN- $\gamma$ ), tumor necrosis factor (TNF), interleukin-12p70 (IL-12p70), and monocyte chemotactic protein 1 (MCP-1)). When the capture beads and detector reagent are incubated with samples, sandwich complexes are formed. These complexes can be measured using flow cytometry to identify particles with the fluorescence characteristics of both the bead and the detector. In detail, the cells were treated with different micelles at a final concentration of $83.3 \mu \mathrm{g} / \mathrm{ml}$, and $50 \mu \mathrm{l}$ of the medium in each sample cells was collected at $0.5,3$ and $24 \mathrm{~h}$ and frozen at $-20^{\circ} \mathrm{C}$ before use. Before detection, the mouse inflammation standards were prepared from 0 to $5000 \mathrm{pg} / \mathrm{ml}$. Subsequently, six kinds of beads were mixed and vortexed thoroughly. Fifty microliters of the mouse inflammation standard dilutions or $50 \mu \mathrm{l}$ of samples was added to $50 \mu \mathrm{l}$ of the mixed capture beads. Fifty microliters of the mouse inflammation PE detection reagent was added to each of the mixtures above. After incubating the assay tubes for $2 \mathrm{~h}$ at room temperature (protected from light), $1 \mathrm{ml}$ wash buffer was added to each tube and centrifuged at $200 \mathrm{~g}$ for $5 \mathrm{~min}$. Lastly, the supernatant was carefully aspirated and discarded from each assay tube, and an additional $300 \mu \mathrm{l}$ of wash buffer was added to each assay tube to resuspend the bead pellet before data acquisition with flow cytometry. The data are expressed as average protein concentrations in each group and presented as mean \pm SD $(n=3)$.

\section{Detection of ROS}

The cells were treated with different micelles at a final concentration of $83.3 \mu \mathrm{g} / \mathrm{ml}$ for $24 \mathrm{~h}$. After the cells were trypsinized, centrifuged, and resuspended, different groups were preincubated for 30 min with $1 \times 10^{-7} \mathrm{~mol} /$ $\mathrm{L}$ of DCFH-DA in an incubator at $37^{\circ} \mathrm{C}$ with horizontal agitation. DCFH-DA diffused into cells and was hydrolyzed into nonfluorescent 2'-7'-dichlorofluorescin (DCF). DCF fluorescence was detected at $530 \mathrm{~nm}$ after excitation of cells at $488 \mathrm{~nm}$ using flow cytometry (Beckman Coulter Reagents, USA) [41]. The results are expressed as average fluorescence intensity of cells in each group $(n=3)$.

\section{Toxicity study on Eahy.926 cells Cytotoxicity}

Cytotoxicity was measured using the CCK-8 assay, which is based on the conversion of water-soluble tetrazolium salt, WST-8 (2-(2-methoxy-4-nitrophenyl)-3-(4-nitrophenyl)5-(2,4-disulfophenyl)-2H-tetrazolium, monosodium salt), to a water-soluble formazan dye upon reduction in the presence of an electron carrier by dehydrogenases. Briefly, the cells were treated with various concentrations (5.28, 20.8 and $83.3 \mu \mathrm{g} / \mathrm{ml}$ ) of PEG-PG-PCL, PEEP-PCL, PEGPCL and PEG-DSPE micelles for $24 \mathrm{~h}$ at $37^{\circ} \mathrm{C}$ or treated with medium as control. Subsequently, $10 \mu \mathrm{l}$ of WST- 8 solution was added to the medium and incubated for an additional $2 \mathrm{~h}$ at $37^{\circ} \mathrm{C}$. The absorbance was determined using a Thermo Scientific multiscan FC microplate photometer at the wavelength of $450 \mathrm{~nm}$. The data are expressed as the percentages of surviving cells compared to the survival of the control group (cells treated with medium as $100 \%)$ and presented as mean \pm SD $(n=4)$.

\section{Apoptosis}

Apoptosis analyses were performed by the Annexin VFITC and PI double staining method [42]. Double staining for both Annexin V-FITC binding and cellular DNA using PI was performed as follows: Cells $\left(5 \times 10^{6}\right.$ cells per $\left.\mathrm{ml}\right)$ treated with different micelles at $83.3 \mu \mathrm{g} / \mathrm{ml}$ for $24 \mathrm{~h}$ were centrifuged, and the resulting pellet was resuspended in PBS. Cells in PBS were centrifuged again and the pellet was resuspended in binding buffer (10 mM 2-[4-(2Hydroxyethyl)-1-piperazinyl]ethanesulfonic acid (HEPES)/ $\mathrm{NaOH}, \mathrm{pH} 7.4,150 \mathrm{mM} \mathrm{KCl}, 1 \mathrm{mM} \mathrm{MgCl}_{2}$ and $1.8 \mathrm{mM}$ $\mathrm{CaCl}_{2}$ ). Annexin V-FITC was added to the pellet, resulting in a final concentration of $2.5 \mu \mathrm{g} / \mathrm{ml}$. The mixture was incubated in the dark at room temperature for $10 \mathrm{~min}$. PI $(1 \mathrm{mg} / \mathrm{ml}$ ) was added $5 \mathrm{~min}$ before flow cytometric analysis, resulting in a final concentration of $50 \mu \mathrm{g} / \mathrm{ml}$. The data are expressed as the percentages of early apoptotic, late apoptotic and necrotic cells and presented as mean \pm $\mathrm{SD}(\mathrm{n}=3)$.

\section{Cell membrane fluidity}

DPH was used to monitor the plasma membrane fluidity of Eahy.926 cells [43]. Labeling of treated cells by the method above was performed by incubating $2 \times 10^{-6} \mathrm{~mol} / \mathrm{L}$ $\mathrm{DPH}$ in 2,5-dimethylfuran. The suspension was allowed to equilibrate for $30 \mathrm{~min}$ at $37^{\circ} \mathrm{C}$. Fluorescence polarization was measured using the Perkin Elmer 650-40 spectrofluorometer. The degree of fluorescence polarization, $\mathrm{P}$, defined in the following equation, was directly recorded.

$\mathrm{P}=\left(\mathrm{I}_{\mathrm{v}}-\mathrm{I}_{\mathrm{h}}\right) /\left(\mathrm{I}_{\mathrm{v}}+\mathrm{I}_{\mathrm{h}}\right)$, where $\mathrm{I}_{\mathrm{v}}$ and $\mathrm{I}_{\mathrm{h}}$ are the emission intensities passing polarizers oriented vertically and horizontally, respectively, with respect to the vertical polarization vector of the exciting light. The data were represented 
by the average $\mathrm{P}$ value of each group and presented as mean \pm SD $(n=3)$.

\section{Toxicity study on KM mice}

\section{Micelles administration and sampling}

Forty mice were randomly divided into five groups (8 mice/group). Four kinds of micelles (i.e., PEG-PG-PCL, PEEP-PCL, PEG-PCL and PEG-DSPE micelles) and saline (control group) were i.v. (tail vein) injected every 48 hours, 4 times $(8 \mathrm{mg} / \mathrm{kg}$ each time), respectively. Body weight and behaviors were recorded every other day post-exposure. On the 8th day post-exposure, the mice were sacrificed, and blood/organ samples were collected. The blood samples were used to complete blood counts and lymphocyte subset analyses. The organs (liver, lung, heart, kidney, thymus and spleen) were obtained for pathological observation.

\section{Complete blood count}

Blood samples were collected by a certified phlebotomist from orbit into blood collection tubes [44]. A mixture of $20 \mu \mathrm{l}$ whole blood and $1 \mathrm{ml}$ dilute solution was used to assess the following: white blood cells (WBC), intermediate cells (MID), lymphocytes (LYM), platelets (PLT), hemoglobin (HGB), red blood cells (RBC) and granulocytes (GRN). All blood samples were tested using a MEK-6318 K (Nihon Kohden, Japan) autoanalyzer.

\section{Lymphocyte subsets}

The peripheral blood ( $1 \mathrm{ml} /$ mouse) was collected in heparinized tubes for all of the experiments [45]. One hundred microliters of blood was incubated in the dark for $30 \mathrm{~min}$ with the following antigens: $5 \mu \mathrm{l} \mathrm{CD} 3 \mathrm{e}-\mathrm{PerCP}$, $2 \mu \mathrm{l} \mathrm{CD4-FITC} \mathrm{and} 5 \mu \mathrm{l} \mathrm{CD8a-PE.} \mathrm{An} \mathrm{additional} 100 \mu \mathrm{l}$ was incubated with $5 \mu \mathrm{l} \mathrm{CD3e-PerCP}$ and $2 \mu \mathrm{l} \mathrm{CD19-}$ FITC. Using the double labeling technique, $\mathrm{CD}^{+} \mathrm{CD}^{+}$, $\mathrm{CD}^{+} \mathrm{CD}^{+}$, and $\mathrm{CD}^{+} \mathrm{CD} 19^{+}$cell subsets were assayed. The erythrocytes were lysed with lysing solution (HLAB27 Kit, BD), and the cells were washed twice with PBS. The samples were counted using a flow cytometer (Beckman Coulter Reagents, USA).

\section{Detection of inflammatory factors in plasma}

Plasma samples were collected from centrifuged peripheral blood, $100 \mu \mathrm{l}$ per sample. The same method of cytometric bead array was performed to detect the inflammatory factors as above described.

\section{Histological observations}

For histological observations, organ samples (heart, liver, spleen, lung, kidney and thymus) were fixed in a $4 \%$ formaldehyde solution, paraffin-embedded, thin-sectioned, and mounted on glass microscope slides using the standard histopathological techniques. The mounted sections were stained with hematoxylin-eosin (H\&E) and examined using light microscopy.

\section{Statistical analysis}

All data are presented as the means of individual observations with the standard deviation. The significance has been calculated using one-way ANOVA. The differences were considered to be significant if $p<0.05$.

\section{Competing interests}

The authors declare that they have no competing interests.

\section{Authors' contributions}

BZ and XYW performed research. BZ, XQW, HNW, QZ designed \& analyzed \& interpreted data, and wrote the manuscript. $\mathrm{HZ}$ and WBD interpreted data and reviewed the manuscript. JW and ZLZ provided PEEP-PCL and PEG-PG-PCL polymers. All authors read and approved the final manuscript.

\section{Acknowledgements}

This study was supported by the National Basic Research Program of China (No. 2009CB930300), the National Natural Science Foundation of China (No. 81273456, 81130059) and Innovation Team of Ministry of Education (No. BMU20110263).

\section{Author details}

${ }^{1}$ State Key Laboratory of Natural and Biomimetic Drugs, School of Pharmaceutical Sciences, Peking University, Beijing 100191, China. ${ }^{2}$ Medical and Healthy Analytical Center, Peking University, Beijing 100191, China. ${ }^{3}$ National Laboratory for Physical Sciences at Microscale and School of Life Sciences, University of Science and Technology of China, Hefei, Anhui 230027, China. ${ }^{4}$ Key Laboratory of Biomedical Polymers of Ministry of Education, Department of Chemistry, Wuhan University, Wuhan 430072 , China.

Received: 27 May 2013 Accepted: 1 October 2013 Published: 3 October 2013

\section{References}

1. Gajewicz A, Rasulev B, Dinadayalane TC, Urbaszek P, Puzyn T, Leszczynska D, Leszczynski J: Advancing risk assessment of engineered nanomaterials: application of computational approaches. Adv Drug Deliv Rev 2012, 64:1663-1693.

2. Linkov I, Steevens J, Adlakha-Hutcheon G, Bennett E, Chappell M, Colvin V, Davis JM, Davis T, Elder A, Hansen S, Hakkinen PB, Hussain SM, Karkan D, Korenstein R, Lynch I, Metcalfe C, Ramadan AB, Satterstrom FK: Emerging methods and tools for environmental risk assessment, decision-making, and policy for nanomaterials: summary of NATO advanced research workshop. J Nanopart Res 2009, 11:513-527.

3. Agasti SS, Rana S, Park MH, Kim CK, You CC, Rotello VM: Nanoparticles for detection and diagnosis. Adv Drug Deliv Rev 2010, 62:316-328.

4. Das A, Mukherjee P, Singla SK, Guturu P, Frost MC, Mukhopadhyay D, Shah $\mathrm{VH}$, Patra CR: Fabrication and characterization of an inorganic gold and silica nanoparticle mediated drug delivery system for nitric oxide. Nanotechnology 2010, 21:305102.

5. Mukherjee P: Targeted delivery using inorganic nanosystem. Preface. Adv Drug Deliv Rev 2010, 62:283.

6. Cormode DP, Jarzyna PA, Mulder WJ, Fayad ZA: Modified natural nanoparticles as contrast agents for medical imaging. Adv Drug Deliv Rev 2010, 62:329-338.

7. Artiles MS, Rout CS, Fisher TS: Graphene-based hybrid materials and devices for biosensing. Adv Drug Deliv Rev 2011, 63:1352-1360.

8. Venkataraman S, Hedrick JL, Ong ZY, Yang C, Ee PL, Hammond PT, Yang YY: The effects of polymeric nanostructure shape on drug delivery. Adv Drug Deliv Rev 2011, 63:1228-1246.

9. Yen HJ, Hsu SH, Tsai CL: Cytotoxicity and immunological response of gold and silver nanoparticles of different sizes. Small 2009, 5:1553-1561.

10. Jones CF, Grainger DW: In vitro assessments of nanomaterial toxicity. Adv Drug Deliv Rev 2009, 61:438-456. 
11. Park SJ, Park YC, Lee SW, Jeong MS, Yu KN, Jung H, Lee JK, Kim JS, Cho MH: Comparing the toxic mechanism of synthesized zinc oxide nanomaterials by physicochemical characterization and reactive oxygen species properties. Toxicol Lett 2011, 207:197-203.

12. Tian F, Cui D, Schwarz H, Estrada GG, Kobayashi H: Cytotoxicity of singlewall carbon nanotubes on human fibroblasts. Toxicol In Vitro 2006, 20:1202-1212.

13. Magrez A, Kasas S, Salicio V, Pasquier N, Seo JW, Celio M, Catsicas S, Schwaller B, Forro L: Cellular toxicity of carbon-based nanomaterials. Nano Lett 2006, 6:1121-1125.

14. Aillon KL, Xie Y, El-Gendy N, Berkland CJ, Forrest ML: Effects of nanomaterial physicochemical properties on in vivo toxicity. Adv Drug Deliv Rev 2009, 61:457-466.

15. Rittner K, Benavente A, Bompard-Sorlet A, Heitz F, Divita G, Brasseur R, Jacobs E: New basic membrane-destabilizing peptides for plasmid-based gene delivery in vitro and in vivo. Mol Ther 2002, 5:104-114.

16. Hong S, Bielinska AU, Mecke A, Keszler B, Beals JL, Shi X, Balogh L, Orr BG, Baker JJ, Banaszak HM: Interaction of poly(amidoamine) dendrimers with supported lipid bilayers and cells: hole formation and the relation to transport. Bioconjug Chem 2004, 15:774-782.

17. Stasko NA, Johnson CB, Schoenfisch MH, Johnson TA, Holmuhamedov EL: Cytotoxicity of polypropylenimine dendrimer conjugates on cultured endothelial cells. Biomacromolecules 2007, 8:3853-3859.

18. Poland CA, Duffin R, Kinloch I, Maynard A, Wallace WA, Seaton A, Stone V, Brown S, Macnee W, Donaldson K: Carbon nanotubes introduced into the abdominal cavity of mice show asbestos-like pathogenicity in a pilot study. Nat Nanotechnol 2008, 3:423-428.

19. Yang ST, Wang X, Jia G, Gu Y, Wang T, Nie H, Ge C, Wang H, Liu Y: Longterm accumulation and low toxicity of single-walled carbon nanotubes in intravenously exposed mice. Toxicol Lett 2008, 181:182-189.

20. Fischer HC, Chan WCW: Nanotoxicity: the growing need for in vivo study. Curr Opin Biotechnol 2007, 18:565-571.

21. Dobrovolskaia MA, McNeil SE: Immunological properties of engineered nanomaterials. Nat Nanotechnol 2007, 2:469-478.

22. Naahidi S, Jafari M, Edalat F, Raymond K, Khademhosseini A, Chen P: Biocompatibility of engineered nanoparticles for drug delivery. J Control Release 2013, 166:182-194.

23. Verma A, Stellacci F: Effect of surface properties on nanoparticle-cell interactions. Small 2010, 6:12-21.

24. Duncan R: The dawning era of polymer therapeutics. Nat Rev Drug Discov 2003, 2:347-360

25. Zhang XJ, Cheng J, Wang QR, Zhong ZL, Zhuo RX: Miktoarm copolymers bearing one poly(ethylene glycol) chains on a hyperbranched polyglycerol core. Macromolecules 2010, 43:6671-6677.

26. Zhang XJ, Zhong ZL, Zhuo RX: Amphiphilic linear-hyperbranched block copolymers one poly(ethylene glycol) chain and several linear poly( $\varepsilon$ caprolactone) chains. J Controled Release 2011, 152:118-119.

27. Wang $Y C$, Liu $X Q$, Sun $T M$, Xiong $M H$, Wang J: Functionalized micelles from block copolymer of polyphosphoester and poly(epsiloncaprolactone) for receptor-mediated drug delivery. J Control Release 2008, 128:32-40.

28. Wang F, Wang YC, Yan LF, Wang J: Biodegradable vesicular nanocarriers based on poly( $\varepsilon$-caprolactone)-block-poly(ethyl ethylene phosphate) for drug delivery. Polymer 2009, 50:5048-5054.

29. Li RT, Li XL, Xie L, Ding D, Hu Y, Qian XP, Yu LX, Ding YT, Jiang XQ, Liu BR. Preparation and evaluation of PEG-PCL nanoparticles for local tetradrine delivery. Int J Pharm 2009, 379:158-166.

30. Zeng N, Hu Q, Liu Z, Gao X, Hu R, Song Q, Gu G, Xia H, Yao L, Pang Z, Jiang $X$, Chen J, Fang L: Preparation and characterization of paclitaxel-loaded DSPE-PEG-liquid crystalline nanoparticles (LCNPs) for improved bioavailability. Int J Pharm 2012, 424:58-66.

31. Yokel RA, Macphail RC: Engineered nanomaterials: exposures, hazards, and risk prevention. J Occup Med Toxicol 2011, 6:7.

32. Golli-Bennour EE, Bouslimi A, Zouaoui O, Nouira S, Achour A, Bacha H: Cytotoxicity effects of amiodarone on cultured cells. Exp Toxicol Pathol 2012, 64:425-430.

33. Tseng SK, Chang MC, Su CY, Chi LY, Chang JZ, Tseng WY, Yeung SY, Hsu $\mathrm{ML}$, Jeng JH: Arecoline induced cell cycle arrest, apoptosis, and cytotoxicity to human endothelial cells. Clin Oral Investig 2012, $16: 1267-1273$
34. Gao XM: A foundation course of immunology. 1st edition. Beijing, China: Edited by Higher Education Press; 2006:45.

35. Chithrani BD, Chan WC: Elucidating the mechanism of cellular uptake and removal of protein-coated gold nanoparticles of different sizes and shapes. Nano Lett 2007, 7:1542-1550.

36. Yu C, He B, Xiong MH, Zhang H, Yuan L, Ma L, Dai WB, Wang J, Wang XL, Wang $X Q$, Zhang $Q$ : The effect of hydrophilic and hydrophobic structure of amphiphilic polymeric micelles on their transport in epithelial MDCK cells. Biomaterials 2013, 34:6284-6298.

37. Vinatier D, Dufour P, Subtil D: Apoptosis: a programmed cell death involved in ovarian and uterine physiology. Eur J Obstet Gynecol Reprod Biol 1996, 67:85-102.

38. Lewinski N, Colvin V, Drezek R: Cytotoxicity of nanoparticles. Small 2008, 4:26-49.

39. Zhao SS, Dai WB, He B, Wang JC, He ZG, Zhang X, Zhang Q: Monitoring the transport of polymeric micelles across MDCK cell monolayer and exploring related mechanisms. J Control Release 2012, 158:413-423.

40. Jiménez R, Ramírez R, Carracedo J, Agüera M, Navarro D, Santamaría R, Pérez R, Del CD, Aljama P: Cytometric bead array (CBA) for the measurement of cytokines in urine and plasma of patients undergoing renal rejection. Cytokine 2005, 32:45-50.

41. Caldefie-Chézet F, Walrand S, Moinard C, Tridon A, Chassagne J, Vasson MP: Is the neutrophil reactive oxygen species production measured by luminol and lucigenin chemiluminescence intra or extracellular? Comparison with DCFH-DA flow cytometry and cytochrome c reduction. Clin Chim Acta 2002, 319:9-17.

42. Ishaque A, Al-Rubeai M: Use of intracellular $\mathrm{pH}$ and annexin-V flow cytometric assays to monitor apoptosis and its suppression by bcl-2 over-expression in hybridoma cell culture. J Immunol Methods 1998, 221:43-57.

43. Pozzi D, Lisi A, Grimaldi S: Role of Akata cell membrane fluidity in susceptibility to Epstein-Barr virus infection. Res Virol 1995, 146:301-305.

44. Flouris AD, Poulianiti KP, Chorti MS, Jamurtas AZ, Kouretas D, Owolabi EO, Tzatzarakis MN, Tsatsakis AM, Koutedakis Y: Acute effects of electronic and tobacco cigarette smoking on complete blood count. Food Chem Toxicol 2012, 50:3600-3603.

45. Bongioanni P, Fioretti C, Vanacore R, Bianchi F, Lombardo F, Ambrogi F, Meucci G: Lymphocyte subsets in multiple sclerosis: a study with twocolour fluorescence analysis. J Neurol Sci 1996, 139:71-77.

doi:10.1186/1743-8977-10-47

Cite this article as: Zhao et al:: Nanotoxicity comparison of four amphiphilic polymeric micelles with similar hydrophilic or hydrophobic structure. Particle and Fibre Toxicology 2013 10:47.

\section{Submit your next manuscript to BioMed Central and take full advantage of:}

- Convenient online submission

- Thorough peer review

- No space constraints or color figure charges

- Immediate publication on acceptance

- Inclusion in PubMed, CAS, Scopus and Google Scholar

- Research which is freely available for redistribution 